\title{
At the Intersection of Vision and Research
}

\section{Chuck Ingoglia}

At the National Council, our vision is one of radical change, "To make mental wellbeing, including recovery from substance use challenges, a reality for everyone." ${ }^{1}$ As we work to make that vision reality, we touch the lives of so many people: those who are facing mental health or substance use challenges; their families and loved ones; policymakers making critical decisions about where to spend their limited health care resources; the public who are hungry for accurate information; and, of course, our National Council members.

As president and CEO, I spend a lot of time talking to our members who represent the diverse mental health and substance use treatment organizations across the nation. Even though I'm no longer on the frontlines, they're my link to the incredible work they're doing every day. And they're my inspiration!

But one group I don't talk to enough is the researchers who are represented here in the $J B H S \& R$. And that's a shame. They are seeking out the truth, challenging the status quo, and paving the way for the future of health and mental health and substance use treatment. So, it's especially gratifying when I look through the pages of this issue of the $J B H S \& R$ and see the many ways our work is intersecting to make a difference in the lives of people, especially those who are at greatest risk.

People with mental illnesses and addictions smoke half of all cigarettes produced. That staggering statistic is even more chilling when you consider that smoking-related illnesses cause half of all deaths among people with mental health and substance use challenges. Yet, despite the risk, this population is only half as likely as other smokers to quit. ${ }^{2}$

Benjamin Brady and his colleagues conducted a retrospective cohort study of Arizona Smokers' Helpline clients examining the association between insurance status, treatment, and smoking cessation. ${ }^{3}$ They found that use of medication and insurance status had little bearing on cessation results, but clients who received three or more coaching sessions had significantly higher odds of quitting compared to those who had fewer than three coaching sessions.

Recognizing the critical need to strengthen the capacity of health care professionals to develop and implement efforts focused on eliminating tobacco- and cancer-related disparities among people with mental illnesses and addictions, the National Council operates the National Behavioral

Address correspondence to Chuck Ingoglia, President \& CEO, National Council for Mental Wellbeing, Washington, DC, USA.kmenendez@usf.edu.

The Journal of Behavioral Health Services \& Research, 2022. 1-3. (c) 2022, National Council for Mental Wellbeing, . DOI 10.1007/s11414-022-09786-4 
Health Network for Tobacco \& Cancer Control (NBHN), ${ }^{4}$ one of eight Centers for Disease Control and Prevention (CDC) national networks ${ }^{5}$ to advance commercial tobacco use prevention and cancer prevention.

Since 2013, NBHN has provided its members with numerous resources to support these efforts, such as training and technical assistance (educational sessions, webinars, and presentations), partnerships, and collaboration (including custom consultation with the CDC and other key stakeholders), state strategy sessions, and tobacco and cancer control communities of practice. Today, NBHN represents 1500 individual members representing community mental health centers, state governments, public health agencies, hospitals and federally qualified health centers providing training and technical assistance, partnerships and collaboration, state strategy sessions, and communities of practice.

The National Council has been proactive in supporting our organizational members since the first tentative days of the COVID-19 global pandemic, supplying resources to help them keep their doors open, their staff safe, and their communities healthy as they navigate an incredibly complex and rapidly evolving public health crisis. We distributed 2.3 million masks at the peak of the shortage of personal protection equipment (PPE), kept on the cutting edge of financial opportunities like tax incentives and loans, fought to expand access to telehealth, and so much more. ${ }^{6}$ All the while, we were acutely aware of the toll the pandemic was taking on employees at high risk of emotional fatigue and burnout.

So, I was especially interested in the work of Michal Ziarko and colleagues exploring the relationship between health care workers' stress levels and mental health in the context of coping with stress during the COVID-19 pandemic. $^{7}$ If, as their study indicates, these unrelenting levels of stress lead to deteriorating health in the long term, it is essential that we find new and more effective ways of responding to protect our most valued asset-our staff.

In April, a Washington Post-Kaiser Family Foundation survey ${ }^{8}$ found almost $60 \%$ of all health care workers nationally had their mental health significantly impacted during the COVID-19 pandemic. A recent report issued by the CDC found that $53 \%$ of public health workers have experienced symptoms of depression, anxiety, PTSD, and suicidal ideation during the pandemic. ${ }^{9}$

The National Council's response matters. It's not enough to hand out masks and hand sanitizer. Providing meaningful resources also requires developing a culture of support through programs to boost mental health, especially for our at-risk mental health and substance use treatment providers. Our webinars, blogs, consultations, and training all make a difference. But it's up to us to explore new ways to support those who chose to work in this rewarding, but frustrating field.

At the National Council, we talk a lot about Certified Community Behavioral Health Clinics (CCBHCs). We are outspoken supporters and champions of the model. And it's no wonder integrated care is the future of health care. As Rachel Petts and her team discovered in their examination of patient and provider experiences at a Federally Qualified Health Center (FQHC), while integrated care is good for both patients and providers, it's not without its challenges. ${ }^{10}$

Our CCBHC Success Center ${ }^{11}$ celebrates our success, but we don't shy away from those challenges. More importantly, we help CCBHCs meet and overcome challenges with implementation and operational support, advocacy initiatives, current data, and general information. Want to find a CCBHC? Go to our CCBHC Locator Tool. ${ }^{12}$ With a few clicks of the mouse, you can learn about one of the $340 \mathrm{CCBHCs}$ across the country. By the time you read this Reflection, there will undoubtably be more.

We often say that we're stronger together. The intersection of research and the vision of the National Council is proof of how strong we can become together and how much we will change with our combined strength. 


\section{References}

1. National Council for Mental Wellbeing. About the National Council. n.d. Available online at https://www.thenationalcouncil.org/about/ national-council/. Accessed 15 Sept 2021

2. National Council for Mental Wellbeing. Tobacco Cessation. n.d. Available online at https://www.thenationalcouncil.org/topics/tobac co-cessation/. Accessed 15 Sept 2021

3. Brady BR, O'Connor PA, Martz MP, et al. Medicaid-insured client characteristics and quit outcomes at the Arizona smokers' helpline. Journal of Behavioral Health Services \& Research. 2021;49(1).

4. National Behavioral Health Network for Tobacco \& Cancer Control. About the National Behavioral Health Network for Tobacco \& Cancer Control. n.d. Available online at https://www.bhthechange.org/about/. Accessed 15 Sept 2021

5. Centers for Disease Control and Prevention. Networking2Save (DP18-1808). 2021, July 30. Available online at https://www.cdc.gov/ cancer/ncccp/related-programs/Networking2Save.htm. Accessed 15 Sept 2021

6. National Council for Mental Wellbeing. Resources and Tools for Addressing Coronavirus (COVID-19). n.d. Available online at https:// www.thenationalcouncil.org/covid19/. Accessed 15 Sept 2021

7. Ziarko M, Jasielska A, Stanisławska-Kubiak M, et al. Mental health outcomes associated with COVID-19 pandemic in a group of health care professionals. Journal of Behavioral Health Services \& Research. 2021;49(1).

8. The Washington Post. KFF frontline health-care workers survey, Feb. 11-March 7, 2021. 2021, April 22. Available online at https:// www.washingtonpost.com/context/washington-post-kff-frontline-health-care-workers-survey-feb-11-march-7-2021/ba15a233-949547a9-9cdd-e7fa1578b1ca/. Accessed 15 Sept 2021

9. Bryant-Genevier J, Rao CY, Lopes-Cardozo B, et al. Morbidity and Mortality Weekly Report. 2021; 25: 70(26). Available online at https://www.cdc.gov/mmwr/volumes/70/wr/mm7026e1.htm. Accessed 15 Sept 2021

10. Petts RA, Lewis RK, Brooks K, et al. Examining patient and provider experiences with integrated care at a community health clinic. Journal of Behavioral Health Services \& Research. 2021;49(1).

11. National Council for Mental Wellbeing. CCBHC Success Center: Overview. n.d. Available online at https://www.thenationalcouncil. org/ccbhc-success-center/ccbhcta-overview/. Accessed 15 Sept 2021

12. National Council for Mental Wellbeing. CCBHC Locator. n.d. Available online at https://www.thenationalcouncil.org/ccbhc-succe ss-center/ccbhc-locator/. Accessed 15 Sept 2021

Publisher's Note Springer Nature remains neutral with regard to jurisdictional claims in published maps and institutional affiliations. 